\title{
Maternal Mortality in the Gynecology-Obstetric Department at the Yalgado Ouedraogo University Hospital Center (CHUYO), Burkina Faso: About 181 Cases Collected from January $1^{\text {st }}$ to December 31 2016
}

\author{
Sibraogo Kiemtoré1,2, Béwendin Evelyne Komboigo3, André Simporé1,2, Hyacinthe Zamané1,2, \\ Xavier Kaboré ${ }^{2}$, Mikael Zoundi², Boubacar Touré2 ${ }^{2}$ Francoise Millogo ${ }^{1,2}$, Blandine Thiéba ${ }^{1,2}$ \\ ${ }^{1}$ Joseph Ki Zerbo University, Ouagadougou, Burkina Faso \\ ${ }^{2}$ Department of Obstetrics Gynecology in Yalgado Ouedraogo University Hospital Center, Ouagadougou, Burkina Faso \\ ${ }^{3}$ Nazi Boni University, Bobo-Dioulasso, Burkina Faso \\ Email: s3kiemtore@yahoo.fr
}

How to cite this paper: Kiemtoré, S., Komboigo, B.E., Simporé, A., Zamané, H., Kaboré, X., Zoundi, M., Touré, B., Millogo, F. and Thiéba, B. (2020) Maternal Mortality in the Gynecology-Obstetric Department at the Yalgado Ouedraogo University Hospital Center (CHUYO), Burkina Faso: About 181 Cases Collected from January $1^{\text {st }}$ to December $31^{\text {st }}$ 2016. Open Journal of $\mathrm{Ob}$ stetrics and Gynecology, 10, 714-722. https://doi.org/10.4236/ojog.2020.1050065

Received: January 6, 2020

Accepted: May 10, 2020

Published: May 13, 2020

Copyright $\odot 2020$ by author(s) and Scientific Research Publishing Inc. This work is licensed under the Creative Commons Attribution International License (CC BY 4.0).

http://creativecommons.org/licenses/by/4.0/

\section{(c) (i) Open Access}

\begin{abstract}
Objective: To study maternal mortality in the obstetrics and gynecology department at Yalgado Ouedraogo teaching Hospital Center. Patients and Methods: We conducted a cross-sectional retrospective and descriptive study of 181 cases of maternal deaths during study period. The parameters studied were sociodemographic characteristics, the causes of death, the clinical data and the contributing factors. Results: The maternal mortality ratio was 2624 per 100,000 live births. The mean age of death was 26.79 with extremes of 15 years to 40 years. Direct obstetric causes accounted for 58\% dominated by hypertension and complications, hemorrhage during pregnancy and postpartum, and obstetric infections. The indirect obstetric causes were $42 \%$ dominated by non-obstetric infections and chronic anemias. In addition to the delay in consultation and delay in care, the lack of antenatal care was the contributing factor to maternal deaths. Conclusion: Maternal mortality remains a public health problem in view of its high ratio. The reduction of this scourge will inevitably go through a health insurance that will allow the supply of quality care.
\end{abstract}

\section{Keywords}

Maternal Mortality, Causes, Contributing Factors, CHU YO 


\section{Introduction}

Pregnancy is a normal condition that most women aspire to during their lifetime. Experience as jovial and exhilarating, give life can be quite dangerous. Maternal mortality is a major public health problem [1]. It remains an obsession not only for women and society but also for practitioners [2].

According to the World Health Organization (WHO), around 830 women die every day in the world because of complications related to pregnancy or childbirth. In 2015, 303,000 women died during or after pregnancy or childbirth [2] [3] [4]. Most of these deaths occurred in poor countries. Indeed the ratio of maternal mortality in 2015 was 239 per 100,000 live births in developing countries compared to 12 per 100,000 live births in developed countries [2] [3]. In Burkina Faso, this ratio was 330 per 100,000 live births [5].

The international community is committed to reducing maternal mortality through the Sustainable Development Goals [5]. In Burkina Faso, several efforts have been made to reduce maternal mortality. Among these efforts, we can mention the awareness of the population, developed systems of delegation of tasks for the management of obstetric and neonatal care emergency (SONU) and free delivery and emergency obstetric care since 2016. Despite the many interventions designed, maternal mortality remains high in Burkina Faso [2] [6].

The present study is a part of the annual review of maternal deaths in the obstetrics and gynecology department at CHUYO. This study aims to analyze the epidemiological, clinical, etiological and therapeutic aspects of maternal mortality in order to better refocus the activities of the department and to draw the attention of the health authorities to the problem.

\section{Patients and Method}

The study took place in the obstetrics and gynecology department at CHUYO. This is a descriptive cross-sectional study with retrospective collection of data. The study included all maternal deaths that occurred between January $1^{\text {st }} 2016$ and December $31^{\text {st }} 2016$ for a one year period. Deaths prior to the patient's arrival in the obstetrics and gynecology department were excluded from the study. The variables studied were age, residence, occupation, and obstetrical history such as parity. Data were collected from patient clinical records, death records, birth registers, hospital records and birth records at the CHUYO maternity ward. The data was entered and analyzed by a microcomputer using the statistical analysis software SPHINX Plus in version 5. The graphics were made using the spreadsheet EXCEL Version 2013. The anonymity and confidentiality of the data have been respected.

\section{Operational definitions:}

Delayed consultation: There was a delay in consultation if there were more than 24 hours between the onset of the first signs of illness in the pregnant woman and the decision to consult in a health center.

Delay in management: There is a delay of care if it has elapsed more than 15 
min between the arrival of the patient and first care.

\section{Results}

\section{Frequency of maternal mortality}

During the study period, the obstetrics and gynecology department at CHUYO registered 11,050 admissions, performed 7351 deliveries with 6897 live births (NV). There were 181 maternal deaths. The mortality ratio was 2624 deaths per $100,000 \mathrm{NV}$.

\section{Socio-demographic characteristics of deceased patients}

\section{- Age}

The average age was $26.6 \pm 6.8$ years with extremes of 15 and 40 years. There were $28(15.5 \%)$ of all early pregnancies (patients under 19 years of age) and 07 (3.9\% of maternal deaths) in late pregnancies (patients over 40 years of age).

\section{- Occupation}

The number of deceased women who had no income-generating activity (housewives and students) was $148 \%$ or $81.8 \%$ of cases.

\section{- Parity}

Parity at the time of death was known in 180 patients. The average parity was $2.1 \pm 2.1$ with extremes of 0 and 11 .

\section{- Residence of deceased patients}

The patients who resided in the central region numbered $99 \%$ or $54.7 \%$. Those from other regions more or less distant were $82 \%$ or $45.3 \%$. The average distance traveled by patients residing outside Ouagadougou was 145.5 kilometers. Table 1 shows the characteristics of the deceased patients.

Table 1. Characteristics of the deceased patients.

\begin{tabular}{|c|c|}
\hline \multicolumn{2}{|l|}{ Characteristics } \\
\hline \multicolumn{2}{|l|}{ Age } \\
\hline - Average (years) & $26.6 \pm 6.8$ \\
\hline - Minimal (years) & 15 \\
\hline - Maximal (years) & 40 \\
\hline - 15 to 19 years old n (\%) & $28(15.5)$ \\
\hline \multicolumn{2}{|l|}{ Occupation n (\%) } \\
\hline - No income-generating activity $n(\%)$ & $148(81.8)$ \\
\hline - Trader & $22(12.2)$ \\
\hline - Employee & $11(6.0)$ \\
\hline \multicolumn{2}{|l|}{ Parity } \\
\hline - Average & $2.1 \pm 2.1$ \\
\hline - Minimal & 0 \\
\hline - Maximal & 11 \\
\hline \multicolumn{2}{|l|}{ Residence } \\
\hline - Ouagadougou & $99(54.7)$ \\
\hline - Outside Ouagadougou & $82(45.3)$ \\
\hline
\end{tabular}




\section{Clinical data}

\section{- Pregnancy monitoring}

The follow-up of the pregnancy was specified in 175 cases. The number of prenatal consultations ranged from 0 to 5 with an average of $1.8 \pm 1.6$.

\section{- Gravido-purperal period at the time of death of the patient}

The distribution of patients who died by the gravid-puerperal period at the time of death is shown in Table 2.

\section{- Place of delivery}

Health facility accounted for 92 cases or $98.9 \%$. A home birth was found in our study.

\section{- Mode of admission}

The patients referred or evacuated were $173 \%$ or $95.6 \%$ of deaths and those who came directly were $8 \%$ or $4.4 \%$.

\section{- Medical causes of death}

The distribution of medical causes of patient deaths is shown in Table 3. Non-obstetric infections included malaria (22 cases), acute meningitis ( 2 cases), pneumonia (11 cases) and hepatitis (4 cases).

Table 2. Distribution of patients deceased by gravity-puerperal period at time of death (n $=181$ ).

\begin{tabular}{ccc}
\hline Périod of gravidity-puerperal & $\mathbf{n}$ & $\%$ \\
\hline During pregnancy & 71 & 39.2 \\
In the post partum & 93 & 51.4 \\
In the post abortum & 16 & 8.8 \\
Broken ectopic pregnancy & 1 & 0.6 \\
Total & $\mathbf{1 8 1}$ & $\mathbf{1 0 0}$ \\
\hline
\end{tabular}

Table 3. Distribution of medical causes of death of patients.

\begin{tabular}{ccc}
\hline Main diagnoses & $\mathbf{n}$ & $\%$ \\
\hline Direct obstetrical complications & 105 & $\mathbf{5 8}$ \\
Hypertensive disorders of pregnancy and its complications & 29 & 16 \\
Bleeding during pregnancy and postpartum & 30 & 16.6 \\
Complications of abortion & 17 & 9.4 \\
Infections obstétric & 27 & 14.9 \\
Other direct obstétric causes & 2 & 1.1 \\
Indirect obstetrical complications & 76 & 42 \\
Chronicanemia & 21 & 11.6 \\
infections not obstétric & 39 & 21.5 \\
Vaso-occlusive crisis & 9 & 5 \\
Other indirect obstétric causes & 7 & 3.9 \\
Total & 181 & 100 \\
\hline
\end{tabular}




\section{Treatment}

Several types of treatment were administered to the patients before deaths. The different treatments received figure in Table 4.

$>$ Time of care

- Time between arrival and first examination

The waiting time between arrival and first examination of the deceased patients ranged from 0 to 45 minutes with an average of 12.6 minutes \pm 10.5 .

\section{- Delay between arrival and start of surgical treatment}

Forty-seven (47) deceased patients had been treated surgically. The patients had undergone surgery (caesarean section, laparotomy). Thirteen women or 37.1\% of cases were supported in the first hour. Three patients (8.3\%) were surgically treated more than 24 hours after the indication was made.

\section{Patient death time}

The average time to death was $47.4 \pm 79.15$ hours. Figure 1 shows the distribution of patients deceased according to the delay of death.

\section{Contributing factors to maternal death}

During our study, several factors contributed to maternal deaths. These include delay in consultation, delay in care and lack of follow-up of pregnancy. These factors had as frequency:

- Delayed consultation: 83 cases or $45.9 \%$;

- The delay in care in the health facilities: 74 cases or $40.8 \%$;

- Lack of antenatal care: 20 cases or $11.0 \%$.

Table 4. Distribution of patients deceased according to the treatment received.

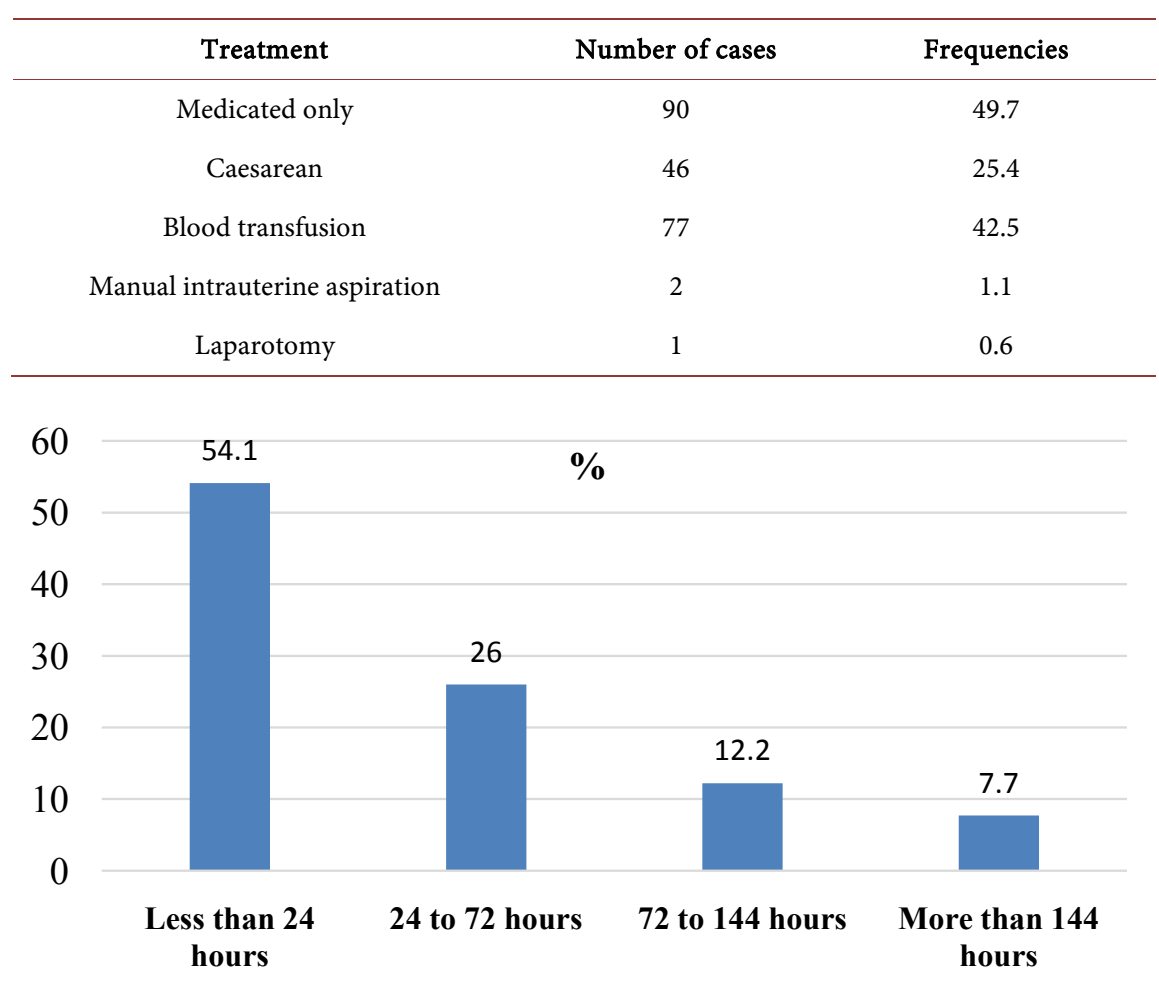

Figure 1. Distribution of patients deceased according to the delay of death $(n=181)$. 
The delay in treatment consisted of the lack of labile blood products and the delay in transfusion (15 cases, $8.3 \%$ ), the lack of financial means with prescription not honored (9 cases, $4.9 \%$ ), delay in occupied block and/or incomplete kit surgery (11 cases or 6.1\%) and evacuation delay for an unavailable ambulance and/or delay in the evacuation procedure (39 cases or $21,5 \%$ ).

\section{Discussion}

The maternal mortality rate was very high in our series (2624 deaths per 100,000 live births). It was 8 times the national rate of the country according to the WHO which was 330 per 100,000 live births but remains lower than that found by Zamané and al [5] which found a rate of 5369 per 100,000 live births at the Dori Regional Hospital Center. This difference can be explained by the fact that our study was conducted in a university hospital where there are many specialists unlike Dori. Our result remains higher than those of other countries such as India, Angola, Nigeria and Gambia which respectively found 2054; 1830; 1791 and 2105 per 100,000 live births [7] [8] [9] [10]. The nature of CHUYO's last resort at the time of the study is to be linked to this extremely high rate of maternal mortality. Similarly, the dysfunction of some surrounding surgical antennas, the usual unavailability of transfusion and operating kit were the main reasons.

Patients who died without any income-generating activity (housewives and students) were $148 \%$ or $81.7 \%$ of cases. This socio professional layer is the most affected as evidenced by Lankoandé et al. [11] who found 94 (76.4\%) deaths among women without a profession. The maternal mortality rate is inversely related to the socio-economic level. Lack of money can affect the health status of women. Women's survival is closely linked to their health [12].

In our study, the number of patients treated or evacuated was $173 \%$ or $95.6 \%$ of deaths. This could be explained by the fact that CHUYO was at the same time as the organization of the health system. The lack of equipment and/or the lack of medical equipment and the lack of medical care of the ambulances in the reference structures on the one hand and the poor condition of the roads on the other hand make evacuations an important factor risk of maternal death.

In our study, direct obstetric causes accounted for $58 \%$ versus $42 \%$ for indirect obstetric causes. We found that Umar et al. in Angola [9] found 51\% of direct obstetric causes versus $49 \%$ of indirect obstetric causes. The direct obstetric causes in this study are the same as those reported in various regions of developing countries [5] [7] [8] [9] [11] [13] [14]. Indeed, haemorrhages (16.6\%) hypertensive disorders and their complications (16\%) and obstetric infections (14.9\%) were the direct causes of maternal deaths in our study. The indirect hand causes of maternal death found in our study were non-obstetric infections (22 cases of malaria, 2 cases of acute meningitis, 11 cases of pneumonia and 4 cases of hepatitis) followed by chronic anemia (11.6\%). Zamané et al. [5], Lankoandé et al. [11] in Burkina Faso, Kaur et al. in India [8] found in their studies that anemia 
was the indirect cause of maternal death. Anemia is most often multifactorial and may be associated with infection [5] [11].

In our study, the majority of patients died within 24 hours of admission. Our results are comparable to those of Lankoandé, Guerrier and Olamijulo who found that most women died within 24 hours of admission [7] [11] [15]. The high rate of maternal mortality in the Department of Obstetrics and Gynecology calls on the health authorities to implement life saving measures such as:

- The establishment of a system of immediate care of patients. Indeed, the longest waiting time between the arrival and the first examination of the deceased patients was 45 minutes in our study. The delay in management was reported in 74 deceased patients, i.e. $40.8 \%$ of cases. The delays in the quality of medical care were positively associated with serious issues for the mother [16].

- The revision of the system of awareness of the population (interest of the follow-up of the pregnancy and the donations of blood). Indeed, in our study, the lack of prenatal follow-up (20 cases, i.e. $11 \%$ ) was one of the maternal contributing factors to death, as was the lack of labile blood products (15 cases, or $8.3 \%)$.

- Universal health insurance. The lack of financial means with prescription not honored (9 cases or $4.9 \%$ ) and the delay to surgery for incomplete kit (11 cases or $6.1 \%$ of cases) were contributing factors to maternal death.

- Improving the system for transferring patients to referral centers. In fact, the delay in evacuation for an unavailable ambulance (39 cases, or $21.5 \%$ of cases) was a contributing factor to the maternal death in our study.

\section{Limitations}

The limits of the study are those of a retrospective study on files sometimes summarily filled up urgently and badly archived. However, valuable information can be drawn for the organization of the department's archives.

\section{Conclusion}

From our study, it appears that maternal mortality remains a public health problem in view of its high ratio. The profile of the woman who dies in the gravid-puerperal period represents the young age and the unfavorable socio-economic status. The medical causes of maternal deaths are mainly direct obstetric causes. As for the contributing factors, we found the delay in admission, the delay in first care, the lack of prenatal follow-up and the lack of financial resources. Despite free care, the record of maternal mortality is still heavy. The reduction of this scourge will inevitably go through a universal health insurance that will allow the provision of quality care.

\section{Conflicts of Interest}

The authors declare no conflicts of interest regarding the publication of this paper. 


\section{References}

[1] Neggers, Y.H. (2016) Trends in Maternal Mortality in the United States. Reproductive Toxicology, 64, 72-76. https://doi.org/10.1016/j.reprotox.2016.04.001

[2] Alkema, L., Chou, D., Hogan, D., Zhang, S., Moller, A.B., Gemmill, A., et al. (2016) Global, Régional and National Levels and Trends in Maternal Mortality between 1990-2015 with Scenario-Based Projections to 2030: A Systematic Analysis by the Maternal Mortality Estimation inter Agency Group. The Lancet, 387, 462-474. https://doi.org/10.1016/S0140-6736(15)00838-7

[3] Lammers, C., Conde-Agudelo, A. and Belizan, J.M. (2004) Maternel-Périnatal Morbidity and Associated with Adolescent Pregnancy in Latin America: Cross-Sectional Study. American Journal of Obstetrics and Gynecology, 192, 342-349. https://doi.org/10.1016/j.ajog.2004.10.593

[4] Ozimek, J.A. and Kilpatrick, S.J. (2018) Maternal Mortality in the Twenty-First Century. Obstetrics and Gynecology Clinics of North America, 45, 175-186. https://doi.org/10.1016/j.ogc.2018.01.004

[5] Zamané, H., Sow, H.E., Kain, D.P., Bicaba, B.W., Kiemtoré, S., Yameogo, I., Bonané-Thieba, B. and Mamadou, S. (2018) Maternal Mortality at the Dori Regional Hospital in Northern Burkina Faso, 2014-2016. International Journal of MCH and AIDS, 7, 235-241. https://doi.org/10.21106/ijma.263

[6] Sombié, I., Méda, Z.C., Blaise Geswendé Savadogo, L., Télesphore Somé, D., Fatoumata Bamouni, S., Dadjoari, M., et al. (2018) Is the Fight against Maternal Mortality in Burkina Faso Adapted to Reduce the Three Delays? Sante Publique, 30, 273-282. https://doi.org/10.3917/spub.182.0273

[7] Guerrier, G., Oluyide, B., Keramorou, M. and Grais, R. (2013) High Maternal and Neonatal Mortality Rates in Northern Nigeria: An 8 Month Observational Study. International Journal of Women's Health, 5, 495-499. https://doi.org/10.2147/IJWH.S48179

[8] Kaur, H., Kaur, S. and Singh, S. (2015) Trends in Maternal Mortality Ratio in a Tertiary Referral Hospital and the Effects of Various Maternity Schemes on It. Journal of Family and Reproductive Health, 9, 89-92.

[9] Umar, A.S. and Kabamba, L. (2016) Maternal Mortality in the Main Referral Hospital in Angola, 2010-2014: Understanding the Context for Maternal Deaths. International Journal of $M C H$ and AIDS, 5, 61-71.

https://doi.org/10.21106/ijma.111

[10] Idoko, P., Anyanwu, M.O. and Bass, S. (2017) A Retrospective Analysis of Trends in Maternal Mortality in a Gambian Tertiary Health Centre. BMC Research Notes, 10, 493. https://doi.org/10.1186/s13104-017-2817-0

[11] Lankoandé, J., Sondo, B., Ouédraogo, C., Ouédraogo, A. and Koné, B. (1997) Maternal Mortality in the National Hospital Center of Ouagadougou (Burkina Faso). Report of 123 Cases Collected in 1995. Revue d Epidémiologie et de Santé Publique, 45, 174-176.

[12] Ouédraogo, A.M., Ouédraogo, H.G., Baguiya, A., Millogo, T., Somé, A. and Kouanda, S. (2016) A Case-Control Study of Risk Factors for Maternal Mortality in Burkina Faso in 2014. International Journal of Gynecology \& Obstetrics, 135, S79-S83. https://doi.org/10.1016/j.ijgo.2016.08.015

[13] Gumanga, S.K., Kolbila, D.Z., Gandau, B.B., Munkaila, A., Malechi, H. and Kyei-Aboagye, K. (2011) Trends in Maternal Mortality in Tamale Teaching Hospital, Ghana. Ghana Medical Journal, 45, 105-110.

[14] MacDorman, M.F., Declercq, E. and Thoma, M.E. (2017) Trends in Maternal Mor- 
tality by Sociodemographic Characteristics and Cause of Death in 27 States and the District of Columbia. Obstetrics \& Gynecology, 129, 811-818.

https://doi.org/10.1097/AOG.0000000000001968

[15] Olamijulo, J.A., Olorunfemi, G., Olaleye, O., Ogedengbe, O.K. and Giwa-Osagie, O.F. (2012) Trends in Maternal Mortality at the Lagos University Teaching Hospital, Lagos, Nigeria. Nigerian Quarterly Journal of Hospital Medicine, 22, 72-79.

[16] Mawarti, Y., Utarini, A. and Hakimi, M. (2017) Maternal Care Quality in Near Miss and Maternal Mortality in an Academic Public Tertiary Hospital in Yogyakarta, Indonesia: A Retrospective Cohort Study. BMC Pregnancy Childbirth, 17, Article No. 149. https://doi.org/10.1186/s12884-017-1326-4 